\title{
ORQUÍDEAS EPIFÍTICAS DE UMA FLORESTA SAZONAL NA ENCOSTA DA SERRA GERAL, ITAARA, RIO GRANDE DO SUL, BRASIL.
}

Tiago Böer Breier

Programa de PG em Botânica, Departamento de Botânica

UFRGS - Porto Alegre, RS

Jumaida Maria Rosito

Departamento de Biologia - CCNE

UFSM - Santa Maria, RS

\section{RESUMO}

São listadas as espécies de Orchidaceae de hábito epifítico ocorrentes em uma Floresta Estacional Decidual na área denominada Centro Tabor, $29^{\circ} 37^{\prime} 30^{\prime \prime}$ S e $53^{\circ} 47^{\prime} 30^{\prime \prime} \mathrm{W}$, na encosta meridional da Serra Geral, município de Itaara, Rio Grande do Sul. Foi constatada a ocorrência de 18 espécies distribuídas em nove gêneros: Bulbophyllum, Capanemia, Cyrtopodium, Gomesa, Isochilus, Lophiaris, Oncidium, Pleurothallis e Sophronitis.

Palavras chave: Orchidaceae, Serra Geral, Floresta Estacional Decidual, Rio Grande do Sul. 


\section{SUMMARY}

The epiphytic Orchidaceae in a seasonal deciduous forest located at the Centro Tabor, $29^{\circ} 37^{\prime} 30^{\prime \prime} \mathrm{S}$ e $53^{\circ} 47^{\prime} 30^{\prime \prime} \mathrm{W}$, Itaara, Serra Geral of the Rio Grande do Sul State were listed. In this research 18 species in eight genera were found: Bulbophyllum, Capanemia, Cyrtopodium, Gomesa, Isochilus, Lophiaris, Oncidium, Pleurothallis and Sophronitis. Key-words: Orchidaceae, Serra Geral, Seasonal Forest, Rio Grande do Sul.

\section{INTRODUÇÃO}

A familia Orchidaceae possui cerca de 725 gêneros e 19.500 espécies, sendo uma das maiores famílias de Magnoliophyta. Com ampla distribuição geográfica, ocorre em todas as regiões do globo, com exceção das regiões polares e desérticas, sendo que a maior diversidade de gêneros e espécies concentra-se nas montanhas tropicais úmidas. $O$ hábito epifítico é uma das principais características da família, incluindo aproximadamente $70 \%$ das suas espécies (BENZING, 1990; DRESSLER, 1993).

Os epífitos vasculares têm importante contribuição florística e ecológica nas florestas tropicais e subtropicais úmidas, sendo considerados uma forma biológica de grande sucesso adaptativo, com representantes em 83 famílias e cerca de 876 gêneros com aproximadamente 29.000 espécies, ou seja $10 \%$ de todas as plantas vasculares. Orchidaceae é a família com maior número de representantes epifíticos, seguida por Bromeliaceae, Araceae e Polypodiaceae (GENTRY \& DODSON, 1987).

Para a região central do Rio Grande do Sul, ou mais precisamente os municípios e localidades vizinhas a Itaara, citações sobre orquídeas epifíticas são encontradas em SCHLECHTER (1925) que refere Octomeria sancti-angeli Kränzl. e Pleurothallis saundersiana Rchb. f. para o município de Silveira Martins; para Santa Maria BELTRÃO (1965) e RAMBO (1965) citam Oncidium cornigerum Lindl.; OLIVEIRA (1991) lista para a

66 Rev. Ciência e Natura, Santa Maria, 21: $65 \quad-75 \quad, 1999$. 
Reserva Biológica do Ibicuí-Mirim, Itaara, os gêneros Capanemia B. Rodr., Oncidium Sw., Phymatidium Lindl., Pleurothallis R. Br. e Sophronitis Lindl.

Com o intuito de contribuir com o conhecimento florístico da região central do Rio Grande do Sul, realizou-se o levantamento das espécies de Orchidaceae epifiticas de uma área de floresta nativa, na encosta meridional da Serra Geral, em Itaara.

\section{MATERIAL E MÉTODOS}

O presente estudo foi realizado na área denominada de Centro Tabor, $29^{\circ} 37^{\prime} 30^{\prime \prime} \mathrm{S}$ e $53^{\circ} 47^{\prime} 30^{\prime \prime} \mathrm{W}$, no município de Itaara (Figura 1). A área compreende um pequeno vale rochoso situado entre $280 \mathrm{~m}$ e $430 \mathrm{~m}$, de altitude na encosta meridional da Serra Geral, num total aproximado de 130 ha, fazendo parte da bacia hidrográfica do Rio Jacuí.

Geologicamente a área de estudo é caracterizada como pertencente ao Cretáceo Inferior, com presença de rochas vulcânicas ácidas (riolitos granofíricos e vitrófiros) e rochas vulcânicas básicas (basaltos e andesitos toleíticos) com intercalações de arenito eólico interderrames (GASPARETO et al., 1988; KAUL, 1990). A Serra Geral no Rio Grande do Sul pertence a unidade geomorfológica Planalto das Araucárias, apresenta uma encosta oriental e uma meridional. A encosta oriental tem uma orientação predominante norte-sul e, nas proximidades de Osório, muda a orientação para leste-oeste (encosta meridional) rebaixando suas cotas altimétricas gradativamente no sentido oeste (HERRMANN \& ROSA, 1990).

O solo é do tipo litólico, pouco desenvolvido, com horizonte $A$ diretamente assentado sobre a rocha ou sobre um pequeno horizonte $\mathrm{C}$, geralmente com muito material de rocha em decomposição (MOSER, 1990).

A região apresenta um clima tipo Cfa, conforme a classificação de Köppen. As chuvas são bem distribuídas, atingindo mais de $100 \mathrm{~mm}$ em todos os meses do ano. A temperatura média do mês mais quente é superior 
a $24^{\circ} \mathrm{C}$, e a do mês mais frio, superior a $14^{\circ} \mathrm{C}$. Uma ocorrência de mais de 10 dias de geada por ano confere um caracter estacional ao regime térmico (MORENO, 1961).

As florestas ocorrentes na encosta da serra, no município de Itaara, são classificadas como Floresta Estacional Decidual, já que a maioria dos indivíduos que compõem o estrato arbóreo emergente perde as folhas no inverno (KLEIN, 1983).

No período de janeiro de 1995 a março de 1996, a área de estudo foi percorrida mensalmente pelas trilhas existentes na mata. Os forófitos de fácil acesso às copas foram escalados mediante a visualização prévia de orquídeas epifíticas, das quais foram coletadas amostras. As plantas encontradas caídas no solo, por desprenderem-se de seu substrato ou por caírem junto com o mesmo, também foram coletadas. O material coletado foi destinado ao cultivo, para posterior herborização, e as flores foram conservadas em álcool $70 \%$, com $5 \%$ de glicerina.

As determinações realizaram-se através de consultas a especialistas, consulta aos herbários (ICN, PACA, HAS e SMDB) e uso de bilbiografias especializadas: COGNIAUX (1896, 1902, 1906); DRESSLER (1993); GARAY \& SATACY (1974); HOEHNE (1940, 1942, 1945, 1949 , 1953); PABST (1972); PABST \& DUNGS (1975, 1977 ); SENGHAS (1998).

\section{RESULTADOS E DISCUSSÃO}

Para a área estudada verificou-se a ocorrência de nove gêneros de orquídeas epifíticas. O gênero com maior número de espécies foi Oncidium, contribuindo com sete espécies. O gênero Pleurothallis contribuiu com três espécies e os gêneros Bulbophyllum, Capanemia, Cyrtopodium, Gomesa, Isochilus, Lophiaris e Sophronitis estão representados por uma espécie. Ao todo foram registradas 18 espécies de orquídeas epifíticas, das quais 16 são citadas pela primeira vez para região central do Rio Grande do 68 Rev. Ciência e Natura, Santa Maria, 21: 65 - 795 , 7999. 
Sul, mais especificamente para Itaara e municípios vizinhos. As duas já registradas são Oncidium cornigerum Lindl., Pleurothallis saundersiana Rchb. f. (Tabela 1).

O número de espécies encontrado para esta floresta interiorana pode ser relacionado com os resultados dos trabalhos de RAMBO (1956) e BRACK et al. (1985), para a Floresta Estacional do Alto Uruguai, com respectivamente 10 e 14 espécies. Já os trabalhos de POTTER \& BACKES (1985), NUNES et al. (1987) NUNES \& WAECHTER (1998), registram, para florestas ocorrentes nos morros graníticos próximos a Porto Alegre, respectivamente 43, 49 e 37 espécies. WAECHTER (1986) registra para florestas da planície costeira em Torres, 66 espécies. Quanto a participação específica dos gêneros, novamente a floresta estudada assemelha-se a Floresta Estacional do Alto Uruguai, onde Oncidium é o gênero mais diversificado (RAMBO, 1956).

Segundo SCHLECHTER (1925) o Rio Grande do Sul é o limite norte de distribuição de muitos táxons de Orchidaceae de hábito terrestre provindos de centros de diversidade situados em regiões mais frias ao sul, e o limite sul de muitos táxons provindos de centros de diversidade situados em regiões mais quentes ao norte. Quantitativamente, o autor conclui que o Estado tem maior influência dos contigentes de migração provindos do norte. WAECHTER (1998) evidencia o limite sul de distribuição geográfica de táxons de Orchidaceae epifíticas ao longo da faixa subtropical costeira, no leste da América do Sul.

O contingente florístico da Encosta Meridional da Serra Geral é proveniente de principalmente três tipos florestais, ou seja, a Floresta Ombrófila Mista, a Floresta Ombrófila Densa e a Floresta Estacional. Decidual. RAMBO $(1951 ; 1961)$ discute que a floresta ombrófila não produziu espécies novas em território sul-riograndens sendo de origem imigrada no Estado. Segundo KLEIN (1983), as espécies do componente arbóreo da Floresta Estacional Decidual da Serra Geral são, em sua maioria, 
provenientes da Floresta Estacional Decidual do Alto Uruguai e do Rio Paraná. Sugere que a flora epifítica, assim como pteridófitas terrestres, tenham seu maior contingente originado da Floresta Ombrófila Densa da Encosta Atlântica, que, contornando a encosta oriental da Serra Geral, adentrou no continente através das florestas (Decidual e Semidecidual) da encosta meridional da Serra Geral.

\section{AGRADECIMENTOS}

Agradecemos a FIPE - UFSM pelo auxílio financeiro e Bolsa concedida; à SOMAH pela concessão para desenvolvimento da pesquisa em sua propriedade; ao Carlos Renato Boelter pela companhia nos trabalhos de campo; ao Dr.Fábio de Barros (pesquisador do Instituto de Botânica, SP); ao Ms. Valter Fraga Nunes (UFRGS), pelo auxílio na determinação do material; ao Dr. Jorge Luiz Waechter (Departamento de Botânica, UFRGS) pela leitura do manuscrito e sugestões; à Ms. Thais Scotti do Canto-Dorow pelo apoio e incentivo.

\section{REFERÊNCIAS BIBLIOGRÁFICAS}

BELTRÃO, R. Flórula fanerogâmica do município de Santa Maria, RS, Brasil.

Boletim do Instituto de Ciências Naturais da Universidade de Santa Maria, Santa Maria, n.2, p.115-152, 1965.

BENZING, D. H. Vascular epiphytes: general biology and related biota. Cambridge: Cambridge University Press, 1990. 354 p.

BRACK, P.; BUENO, R.M.; FALKENBERG, D.B. et al. Levantamento florístico do Parque Estadual do Turvo, Tenente Portela, Rio Grande do Sul, Brasil. Roessléria, Porto Alegre, v.7, n.1, p.69-94, 1985. 
BRADE, A. C., PABST, G. F. J. Index generum et specierum orchidacearum brasiliensium inter 1932 e 1950 descripta sunt. Orquídea, Rio de Janeiro, n.1, p.1-52, 1952.

COGNIAUX, A. Orchidaceae. In: MARTIUS, K. F. P. von ed. Flora Brasiliensis. Monachii: Frid. Fleischer. 1896. v.3, n.4, 672 p.

COGNIAUX, A. Orchidaceae. In: MARTIUS, K. F. P. von ed. Flora Brasiliensis. Monachii: Frid. Fleischer. 1902. v.3, n.5, 664 p.

COGNIAUX, A. Orchidaceae. In: MARTIUS, K. F. P. von ed. Flora Brasiliensis. Monachii: Frid. Fleischer. 1906. v.3, n.6, 604 p.

DRESSLER, R. L. Phylogeny and classification of the orchid family. Portland: Dioscorides Press. 1993. $314 \mathrm{p}$.

GASPARETO, N. V. L.; MEDEIROS, E.R.; VEIGA, P. et al. Mapa geológico da folha de Santa Maria. 1:50.000. Santa Maria, 1988.

GARAY, L. A., SATACY, J. E. Synopsis of the genus Oncidium. Bradea, Rio de Janeiro, v.1, n.40, p.393-428, 1974.

GENTRY, A. H., DODSON, C. H. Diversity and biogeography of neotropical vascular epiphytes. Annals of the Missouri Botanical Garden, v.74, n.2, p.205-233, 1987.

HERRMANN, M. L. P., ROSA, R. O. Relevo. In: IBGE. Geografia do Brasil: Região Sul. Rio de Janeiro. 1990. v.2, p.54-84.

HOEHNE, F. C. Orchidaceae. In: Flora Brasilica. São Paulo: Secretaria de Agricultura / Instituto de Botânica. 1940. v.12, n.1, 254 p.

HOEHNE, F. C. Orchidaceae. In: Flora Brasilica. São Paulo: Secretaria de Agricultura / Instituto de Botânica. 1942. v.12, n.6, 218 p.

HOEHNE, F. C. Orchidaceae. In: Flora Brasilica. São Paulo: Secretaria de Agricultura / Instituto de Botânica. 1945. v.12, n.2, 389 p.

HOEHNE, F. C. Iconografia de orchidaceas do Brasil. São Paulo: Secretaria de Agricultura / Instituto de Botânica. 1949. 301 p. 
HOEHNE, F. C. Orchidaceae. In: Flora Brasilica. São Paulo: Secretaria de Agricultura / Instituto de Botânica. 1953. v.12, n.7, 397 p.

KAUL, P. F. T. Geologia. In: IBGE. Geografia do Brasil: Região Sul. Rio de Janeiro. 1990. v. 2, p.29-53.

KLEIN, R. M. Aspectos fitofisionomicos da floresta estacional da fralda da Serra Geral (RS). In: CONGRESSO NACIONAL DE BOTÂNICA, 34. Anais... Porto Alegre, p.73-110. 1983.

MORENO, J. A. Clima no Rio Grande do Sul. Porto Alegre: Secretaria da Agricultura. $1961.42 \mathrm{p}$.

MOSER, J. M. Solos. In: IBGE. Geografia do Brasil: Região Sul. Rio de Janeiro. 1990. v. 2, p.85-109.

NUNES, V. F., NARDIN, J. L. P., SILVA, T. N. Orchidaceae nativas no Morro Santana, Porto Alegre, RS. In: ENCONTRO DE ORQUIDÓFILOS E ORQUIDÓLOGOS DO BRASIL, 3. Anais... Rio de Janeiro: Expressão e Cultura (no prelo). 1987.

NUNES, V. F., WAECHTER, J. L. Aspectos ecológicos e relações florísticas de Orchidaceae epifíticas de um morro granítico subtropical. Pesquisas, São Leopoldo, n.48, p.157-191, 1998.

OLIVEIRA, M. L. A. A. Dados florísticos preliminares e elaboração da flórula vascular da Reserva Biológica do Ibicuí-Mirim, Santa Maria, Rio Grande do Sul, Brasil. Iheringia, Sér. Bot. Porto Alegre, n.41, p.141-153, 1991.

PABST, G. F. J. Estudos no gênero Oncidium Sw. (Orchidaceae) IV. Bradea, Rio de Janeiro, v.1, n.15, p.139-140, 1972.

PABST, G. F. J., DUNGS, F. Orchidaceae brasilienses. Hildesheim: BrückeVerlag Kurt Schmersow. v. 1. 1975. 408 p.

PABST, G. F. J., DUNGS, F. Orchidaceae brasilienses. Hildesheim: BrückeVerlag Kurt Schmersow. v. 2. 1977. 418 p. 
POTTER, K., BACKES, A. Orquídeas nativas dos morros graníticos da Grande Porto Alegre. Comunicações do Museu de Ciências da PUCRGS. Sér. Bot., Porto Alegre, n.37, p.129-138, 1985.

RAMBO, B. A imigração da selva higrófila no Rio Grande do Sul. Anais Botânicos do Herbário Barbosa Rodrigues, Itajaí, n.3, p. 55-91, 1951.

RAMBO, B. Der Regenwald am oberen Uruguay. Sellowia, Itajaí, n.7, p.183233, 1956.

RAMBO, B. Migration routes of the south Brazilian rain forest. Pesquisas, São Leopoldo, n.12, p.5-54, 1961.

RAMBO, B. Orchidaceae riograndenses. Iheringia, Sér. Bot., Porto Alegre, n.13, p.1-96, 1965.

SCHLECHTER, R. Die Orchideenflora von Rio Grande do Sul. Repertorium Specierum Novarum Regni Vegetabilis, Berlin, n.35, p.1-108, 1925.

SENGHAS, K. Die Orchideen Subtribus Oncidiinae. Berlin: Parey. 257p. v.1/C, n.3. p.2057-2308. 1998.

WAECHTER, J. L. Epífitos vasculares da mata paludosa do Faxinal, Torres, Rio Grande do Sul, Brasil. Iheringia, Sér. Bot., Porto Alegre, n.34, p. 3949, 1986.

WAECHTER, J. L. Epiphytic orchids in eastern subtropical South America. In:WORLD ORCHID CONFERENCE, 15, 1996, Rio de janeiro. Proceedings...Turriers: Naturalia Publications, 1998. P.332-41. 
TABELA 1: Espécies de orchidaceae epifíticas da Floresta do Centro Tabor (Itaara, RS) e seus respectivos números de registro no herbário SMDB da Universidade Federal de Santa Maria (RS).

\begin{tabular}{|c|c|c|}
\hline Subtribos & Espécie & SMDB $n=$ \\
\hline Cyrtopodiinae & Cyrtopodium palmifrons Rchb. f. \& Warm. & 6644 \\
\hline Bulbophyllinae & Bulbophyllum regnellii Rchb. f. & 6645 \\
\hline \multirow[t]{2}{*}{ Laeliinae } & Isochilus linearis (Jacq.) R. Br. & 6646 \\
\hline & Sophronitis cernua Lindl. & 6660 \\
\hline \multirow[t]{2}{*}{ Oncidiinae } & Capanemia superflua (Rchb.f.) Garay & 6647 \\
\hline & Gomesa crispa (Lindl.) KI. \& Rchb. f. & 5604,5605 \\
\hline \multirow[t]{10}{*}{ 一 } & Lophiaris pumila (Lindl.) Braem & 6663 \\
\hline & Oncidium bifolium Sims & 6661 \\
\hline & Oncidium concolor Hook & 6648 \\
\hline & Oncidium cornigerum Lindl. ${ }^{1}$ & 6662 \\
\hline & Oncidium fimbriatum Lindl. & 6649 \\
\hline & Oncidium longipes Lindl. & 6106 \\
\hline & Oncidium macronix Rchb.f. & 6650 \\
\hline & Oncidium paranaense Krzl. & 6651 \\
\hline & Oncidium pumilum Lindl. & 6663 \\
\hline & Oncidium sphegiferum Lindl. & 6652 \\
\hline \multirow[t]{3}{*}{ Pleurothallidinae } & Pleurothallis hygrophila Rodr. & 5600 \\
\hline & Pleurothallis saundersiana Rchb. f. ${ }^{2}$ & 6653 \\
\hline & Pleurothallis saurocephala Lood. & 6654 \\
\hline
\end{tabular}

1- Citada para Santa Maria, RAMBO (1965) e BELTRÃO (1965).

2- Citada para Silveira Martins, SCHLECHTER (1925). 


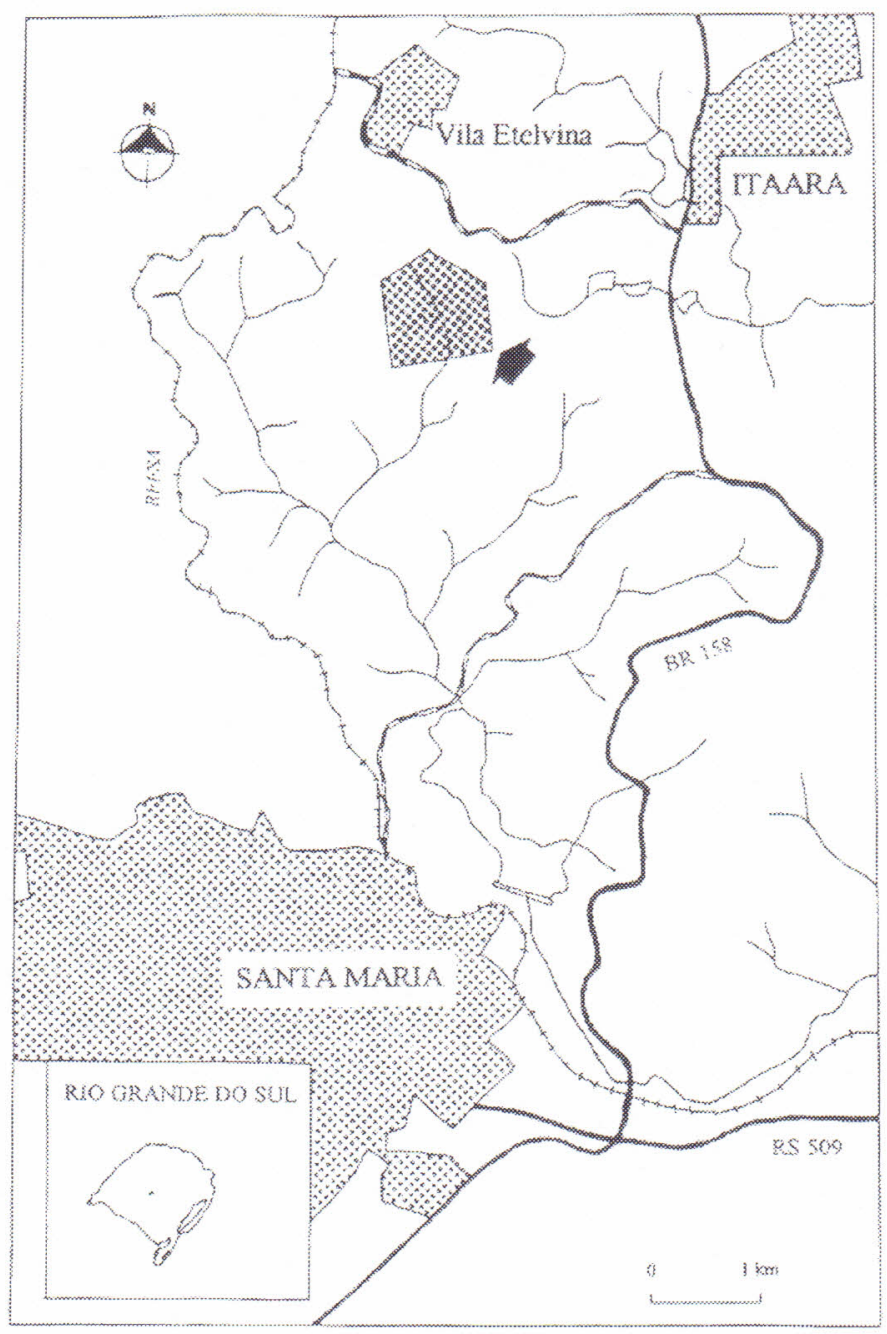

Figura 1: Localização do Centro Tabor (seta) $29^{\circ} 37^{\prime} 30^{\prime \prime} \mathrm{S}$ e $53^{\circ} 47^{\prime} 30^{\prime \prime}$ W (Fonte: Diretoria de Serviço Geográfico. Folha de Santa Maria, SH.22-V-CIV-1).

Rev. Ciência e Natura, Santa Maria, 21: $65 \quad-75$, 1999. 
76 Rev. Ciência e Natura, Santa Maria, 21: 65 - 75 , 1999. 